\title{
ANTIPSYCHOTIC TREATMENT AND METABOLIC ALTERATION IN PATIENTS WITH SCHIZOPHRENIA
}

\author{
Adriana Prifti ${ }^{*}$, Valentina Qemalli ${ }^{2}$, Lidra Zikaj ${ }^{1}$, Etleva Refatllari ${ }^{3}$ \\ ${ }^{1 *}$ Laboratory, Polyclinic of Specialty Nr.3, Tirana, Albania; \\ ${ }^{2}$ Regional Health Authority, Tirana, Albania; \\ ${ }^{3}$ University Hospital Centre "Mother Theresa" Tirana, Albania;
}

*Corresponding author Adriana Prifti, email: adrianaprifti@gmail.com;

Received May, 2018; Accepted May, 2018; Published June, 2018;

DOI: https://doi.org/10.31407/ijees8317

UOI license: http://u-o-i.org/1.01/ijees/33045525

\begin{abstract}
Psychopharmacology has become more complex over the past decade or so, with many more medications available from different pharmacologic classes. To investigate the alterations of biochemical parameters, in patients with schizophrenia and bipolar disorders treated with atypical antipsychotic and antidepressants (Olanzapin, Risperidon, Clozapin, tricyclic antidepressants, SSRI, SNRI). Seventy four patients in prolonged treatment with schizophrenia and bipolar disorders were evaluated, $22(29.7 \%)$ women and $52(70.3 \%)$ men, aged between 11 and 65 years. Blood collection and examination were performed at our laboratory with autoanalysator SAT 450 and MAGLUM 800 PRL.Evaluation after repeated measurements indicated significant differences in comparing the mean values obtained in each patient. The indicators of development of metabolic syndrome showed a significant increase of lipid panel especially triglycerides, total cholesterol, fasting glucose, CK level and hepatic enzymes $(\mathrm{p}<0.01)$. Plasma level of prolactin was significantly higher in patients with the predominant negative symptoms of schizophrenia $4.88( \pm 3.72)$. This study supports the hypothesis that changes in the studied parameters are associated with the treatment with atypical antipsychotic and antidepressant drugs. Monitoring patients' blood compositions could result in better prognostic evaluations and aid in determining additional systemic treatment options.
\end{abstract}

Keywords: Measurements; Biochemical parameters; Schizophrenia; Bipolar disorders 